\title{
The influence of taekwondo training on school-life adaptation and exercise value in the United States
}

\author{
Ik Rae Cho, Hyo Joo Park, Taek Kyun Lee* \\ College of Education, Hankuk University of Foregin Studies, Seoul, Korea
}

Previous experience has shown that school-based taekwondo training in the United States (US) results in many beneficial effect sregarding school education and the physical health of the adolescent participants; of especial significance, the training plays an important role in terms of exercise value and school-life adaptation. To explore this overall effect, a self-administered questionnaire was distributed to 401 adolescents over the age of 10 years. The survey comprisesa total of 29 questions that consist of 17 exercise-value-related questions (general, moral, and status) and 12 questions that are related to school-life adaptation (adaptation to teachers, adaptation to academic activities, adaptation to rule compliance, and adaptation to school activities). The survey results show that taekwondo training affects school-life adaptation by helping to improve student morality and by bolstering the students compliance with school rules during their schooling. The exercise value of taekwondo training is considered a necessity for US adolescents due to the corresponding educational aspects; in particular, the training plays a very important role in the maintenance of amenable student-teacher and student-peer relationships. From the previously mentioned findings, and if taekwondo teachers train their students carefully with educational missions in mind, it is expected that taekwondo training will play a very important role in the cultivation of anappropriate education value among US adolescents.

Keywords: Taekwondo training, Exercise value, School-life, Adaptation

\section{INTRODUCTION}

Education in the United States (US) has been developed on the basis of pragmatism, rationalism, and the rule of law. In particular, the US has sought to foster talent through leadership training based on the premise that the leader's role is the most important factor in the consolidation of a multiethnic country as one; accordingly, the US has strived to improve the value of adolescent education and to encourage democratic citizenship (Watson et al., 1989). As part of these efforts, an increasing number of schools have incorporated taekwondo into their official curriculum to improve the value of education and the citizenship of adolescents.

Taekwondo is a martial art form that originated in Korea and has been adopted as an official Olympic sport since the Sydney Olympics in 2000. It is a popular sport worldwide, with about 80 million individuals from more than 200 countries participating
(Kazemi et al., 2006; Lee and Kim, 2015). The number of children and adults participating in martial arts, including taekwondo, has been increasing by 20\%-25\% annually, and taekwondo is a popular sport among children (Lee and Kim, 2015).

Taekwondo has played a key role in the improvement of a humanist education that values courtesy and respect, as well as in the prevention of a diversity of crimes by contributing to the physical training and values education of American students. In addition, taekwondo has been recognized as one of the most effective methods to cultivate desirable values and attitudes in adolescents through the internalization of social norms, beliefs, values, attitudes, and cognitive experiences (Lim and Kim, 2011).

In general, physical activities affect human social life in various ways, and in herent values directly impact on psychological reactions and achievement behaviors (Schwartz, 1992). As the value of participting in physical activities through sports helps the indi-
${ }^{\star}$ Corresponding author: Taek Kyun Lee (D) https://orcid.org/0000-0001-6090-507X College of Education, Hankuk University of Foreign Studies, 107 Imun-ro, Dongdaemun-gu, Seoul 02450, Korea

Tel: +82-2-2173-3307, Fax: +82-2-2173-3934, E-mail: gotkd99@naver.com Received: January 5, 2018 / Accepted: March 10, 2018
This is an Open Access article distributed under the terms of the Creative Commons Attribution Non-Commercial License (http://creativecommons.org/licenses/by-nc/4.0/) which permits unrestricted non-commercial use, distribution, and reproduction in any medium, provided the original work is properly cited. 
vidual's psychological adaptation and improves social support, we can see that it plays critical role in healthy adaptation to the school life. in this respect, physical activity through taekwondo training is considered very important for school education within the US.

Adolescence is a period characterized by the decreased dependence of a child on his/her parents and the fostering of broader relationships with teachers and friends; furthermore, physical, mental, emotional, moral, and behavioral developments occur during this period. The values and emotional self that develop during this periodresult in adiverse set of impacts regarding an adolescent's life (Kwak and Seo, 2011); therefore, school adaptation is very important in adolescence, and it can be said that a practical education that encourages mutual harmony and care through sports ties is very important. Shootings and drug usage by US middle- and high-school students, however, have become serious social problems, and the nation's educators have consequently shown a greater interest in the incorporation of sporting activities into their educational work. Specifically, american educators have become much more interested in taekwondo training, and increasing numbers of elementary, middle and high schools have attempted to adopt taekwondo training as an official curriculum item.

Taekwondo training in the US was focused on health and physical-strength improvements in the past; however, approaches that address the value of education have recently become more popular In reference to prior studies, taekwondo training during the elementary school period has positive effects on physical, cognitive, emotional, and social development (Chang and Hwang, 2017; Lee and Song, 2006). Taekwondo has positive influences on trainees' psychological constructs such as will power (Kim, 2005), concentration (Kim and Kim, 2000), and self-regulation (Lakes and Hoyt, 2004). Also, taekwondo trainees have a lower acculturative stress level than nontrainees, and cope effectively with it (Kim et al., 2012). Another study on taekwondo elementary school trainees in the US pointed out that taekwondo positively developed sociability and mental health (Lee, 2010). Lakes (2013) stated that the expectation regarding taekwondo training comprises the improvement of exercise capabilities and psychological benefits.

In addition, Lakes et al. (2013) reported that taekwondo training positively affected the self-control, execution functions, class behaviors, and exercise functions of young student subjects. The training also affected the school adaptation of the young students, as they experienced corresponding favorable effects regarding their relationships with teachers, their relationships with friends, and school classes and norms.

This study therefore attempts to elucidate the impact of the exercise value of taekwondo training in the US with respect to school-life adaptation, and to aid the value education of US adolescents by presenting practical guidelines and criterion data.

\section{MATERIALS AND METHODS}

\section{Study subjects}

The study population includes trainees who were aged over 10 years and were undertaking taekwondo training as an after-school physical-education activity in training centers. The centers employed Korean teachers and were located in Illinois in the Midwest of the US. The six largest taekwondo training centers in Illinois were selected by applying cluster sampling through the use of a convenience-sampling method. Self-administration was employed for the answer generation for the questionnaires. A total of 420 questionnaires were distributed and 401 were used for the final analysis, with the exclusion of 19 responses that are in sincere. The demographic characteristics of the study subjects are listed in Table 1.

\section{Research tools}

The study used a questionnaire as the measurement tool and the configuration of the questionnaire is shown in Table 2.

An exploratory factor analysis (EFA) was conducted to test the validity of the configured tool. A principal-component analysis

Table 1. Demographic characteristics of study subjects $(n=401)$

\begin{tabular}{lc}
\hline Sex & No. $(\%)$ \\
\hline Male & $264(65.8)$ \\
Female & $137(34.2)$ \\
\hline
\end{tabular}

Table 2. Configuration of questionnaires

\begin{tabular}{lc}
\hline Variable & No. \\
\hline Training values & 8 \\
General values & 4 \\
Status values & 5 \\
Moral values & \\
Adaptation to school life & 3 \\
Adaptation to teachers & 3 \\
Adaptation to academic activities & 3 \\
Adaptation to rule compliance & 3 \\
Adaptation to school activities & 29 \\
Total &
\end{tabular}


was utilized for the EFA, and factors with unique values of 1.0 or higher were extracted using the VARIMAX method; additionally, the reliability was analyzed using the Cronbach a coefficients. The research-tool configuration with the associated EFA and reliability analysis are below.

First, to evaluate the exercise values of the taekwondo trainees, the sports value scale for youth that is included in the youth sport value questionnaire (Lee and Cockman, 1995; Lee et al., 2000) and the sports value scale for Korean youth that was developed by Seong (2005) were adopted; to suit the purpose of this study, these scales were used to modify the questionnaire that was used by Kim (2012). A total of 17 questions that consist of general (eight questions), moral (five questions), and status (four questions) types were developed. The validity and reliability are shown in Table 3.

Second, to evaluate the adaptation to school life, the questionnaire items that were used by Uu and Won (2008), Kim and Seo (2009), Kim and Kwak (2014) were modified to suit the purpose of this study. A total of 12 questions that were divided into the following categories were used as subscales that represent adaptation to school life: adaptation to teachers (three questions), adaptation to academic activities (three questions), adaptation to school rules (three questions), and adaptation to school activities

Table 3. Validity and reliability of exercise values

\begin{tabular}{lccc}
\hline Factor & General & Status & Moral \\
\hline Exercise value 1 & 0.876 & 0.045 & 0.055 \\
Exercise value 2 & 0.825 & 0.060 & 0.165 \\
Exercise value 3 & 0.813 & 0.096 & 0.145 \\
Exercise value 4 & 0.759 & 0.120 & 0.214 \\
Exercise value 5 & 0.748 & 0.047 & 0.139 \\
Exercise value 6 & 0.740 & 0.135 & 0.269 \\
Exercise value 7 & 0.734 & 0.022 & 0.279 \\
Exercise value 8 & 0.718 & 0.185 & 0.246 \\
Exercise value 14 & 0.064 & 0.876 & 0.139 \\
Exercise value 17 & 0.134 & 0.871 & 0.183 \\
Exercise value 15 & 0.135 & 0.853 & 0.110 \\
Exercise value 16 & 0.068 & 0.833 & 0.107 \\
Exercise value 10 & 0.042 & 0.246 & 0.888 \\
Exercise value 11 & 0.121 & 0.232 & 0.772 \\
Exercise value 13 & 0.320 & 0.051 & 0.685 \\
Exercise value 12 & 0.367 & -0.001 & 0.668 \\
Exercise value 9 & 0.291 & 0.123 & 0.640 \\
Unique value & 5.228 & 3.164 & 3.113 \\
Variance (\%) & 30.754 & 18.610 & 18.312 \\
Cumulative (\%) & 30.754 & 49.364 & 67.676 \\
Cronbach $\alpha$ & 0.922 & 0.899 & 0.834 \\
\hline 1 & 0.896 &
\end{tabular}

KMO (Kaiser-Meyer-Olkin) $=0.874$, Bartlett $\chi^{2}=4,563.614, P=0.000$. (three questions). The validity and reliability are shown in Table 4.

\section{Data analysis}

IBM SPSS Statistics ver. 21.0 (IBM Co., Armonk, NY, USA) was used for the analysis of 401 of the 420 distributed questionnaires of this study. First, to identify the demographic characteristics, a frequency analysis was conducted. To test the validity and reliability of the questionnaires, the EFA and the reliability analysis were conducted. To determine the correlation and effect relationship between the variables, a correlation analysis and a multiple regression analysis were conducted.

\section{RESULTS}

\section{Correlation between the exercise values and adaptation to school life for the taekwondo trainees}

The correlation analysis was conducted using the Pearson correlation test, and examined the relationship between the exercise values of the taekwondo trainees and school-life adaptation; the results are shown in Table 5. An analysis of the correlation between the exercise values of the taekwondo trainees and school-life adaptation show positive $(+)$ correlations for all of the factors.

Impact of the exercise valuesof the taekwondo trainees on school-life adaptation. To examine the impact of the exercise values of US. Taekwondo trainees on school-life adaptation, a multiple regression analysis was conducted and the results are shown in

Table 4. Validity and reliability of the adaptation to school life

\begin{tabular}{lcccc}
\hline Factor & School activities & Teachers & School rules & Academic activities \\
\hline Adaptation 10 & 0.765 & 0.111 & 0.184 & 0.283 \\
Adaptation 12 & 0.738 & 0.239 & 0.280 & 0.064 \\
Adaptation 11 & 0.719 & 0.120 & 0.361 & 0.153 \\
Adaptation 1 & 0.002 & 0.789 & 0.277 & 0.168 \\
Adaptation 2 & 0.238 & 0.764 & 0.194 & 0.207 \\
Adaptation 3 & 0.374 & 0.686 & 0.078 & 0.285 \\
Adaptation 7 & 0.282 & 0.326 & 0.747 & 0.035 \\
Adaptation 9 & 0.278 & 0.120 & 0.695 & 0.314 \\
Adaptation 8 & 0.302 & 0.199 & 0.683 & 0.307 \\
Adaptation 5 & 0.225 & 0.148 & 0.256 & 0.784 \\
Adaptation 4 & 0.121 & 0.344 & 0.148 & 0.743 \\
Adaptation 6 & 0.359 & 0.350 & 0.185 & 0.464 \\
Unique value & 2.367 & 2.183 & 1.991 & 1.836 \\
Variance (\%) & 19.721 & 18.194 & 16.595 & 15.297 \\
Cumulative (\%) & 19.721 & 37.915 & 54.510 & 69.807 \\
Cronbach $\alpha$ & 0.781 & 0.778 & 0.773 & 0.739 \\
\hline
\end{tabular}

KMO (Kaiser-Meyer-Olkin)=0.920, Bartlett $\chi^{2}=2,068.999, P=0.000$. 
Cho IR, et al. • Taekwondo training on school-life adaptation

Table 5. Correlation between exercise values and school-life adaptation

\begin{tabular}{|c|c|c|c|c|c|c|c|}
\hline \multirow{2}{*}{ Variable } & \multicolumn{3}{|c|}{ Exercise } & \multicolumn{4}{|c|}{ School } \\
\hline & Value 1 & Value 2 & Value 3 & Adaptation 1 & Adaptation 2 & Adaptation 3 & Adaptation 4 \\
\hline Exercise value 1 & 1.000 & & & & & & \\
\hline Exercise value 2 & $0.252^{* *}$ & 1.000 & & & & & \\
\hline Exercise value 3 & $0.502^{* *}$ & $0.355^{* *}$ & 1.000 & & & & \\
\hline School adaptation 1 & $0.482^{* *}$ & $0.252^{* *}$ & $0.422^{* *}$ & 1.000 & & & \\
\hline Adaptation 2 & $0.380^{* *}$ & $0.193^{* *}$ & $0.397^{* *}$ & $0.515^{* *}$ & 1.000 & & \\
\hline Adaptation 3 & $0.433^{* *}$ & $0.298^{* *}$ & $0.442^{* *}$ & $0.675^{* *}$ & $0.578^{* *}$ & 1.000 & \\
\hline Adaptation 4 & $0.441^{* *}$ & $0.260^{* *}$ & $0.408^{* *}$ & $0.588 * *$ & $0.638^{* *}$ & $0.621^{* *}$ & 1.000 \\
\hline
\end{tabular}

${ }^{* *} P<0.01$

Table 6. Impact of exercise values on school-life adaptation

\begin{tabular}{lcccccc}
\hline Variable & $B$ & $S E$ & $\beta$ & \multicolumn{1}{c}{$t$} & $R^{2}$ & $F$ \\
\hline $\begin{array}{l}\text { School activities } \\
\text { (constant) }\end{array}$ & 0.456 & 0.282 & - & 1.620 & & \\
General & 0.479 & 0.067 & 0.352 & $7.130^{* * *}$ & & \\
Status & 0.071 & 0.037 & 0.087 & 1.909 & & \\
Moral & 0.265 & 0.063 & 0.214 & $4.191^{* * *}$ & & \\
Teachers & & & & & 0.203 & $33.682^{* * *}$ \\
(constant) & 0.841 & 0.302 & - & 2.786 & & \\
General & 0.329 & 0.072 & 0.238 & $4.567^{* * *}$ & & \\
Status & 0.033 & 0.040 & 0.040 & 0.832 & & \\
Moral & 0.332 & 0.068 & 0.264 & $4.900^{* * *}$ & & \\
Rules & & & & & 0.272 & $49.382^{* * *}$ \\
(constant) & 0.380 & 0.292 & - & 1.302 & & \\
General & 0.376 & 0.070 & 0.268 & $5.398^{* * *}$ & & \\
Status & 0.117 & 0.039 & 0.139 & $3.015^{* *}$ & & \\
Moral & 0.329 & 0.066 & 0.258 & $5.018^{* * *}$ & & \\
Academic activities & & & & & 0.251 & $44.334^{* * *}$ \\
(constant) & 0.528 & 0.288 & - & 1.832 & & \\
General & 0.417 & 0.069 & 0.305 & $6.055^{* * *}$ & & \\
Status & 0.087 & 0.038 & 0.107 & $2.287^{*}$ & & \\
Moral & 0.269 & 0.065 & 0.217 & $4.154^{* * *}$ & & \\
\hline & & & & & &
\end{tabular}

${ }^{*} P<0.05$. ${ }^{* *} P<0.01$. ${ }^{* *} P<0.001$.

Table 6.

For the suitability (goodness of fit) of the model regarding school-activity adaptation for both exercise values and school-life adaptation, the regression model is appropriate at thelevel of $F=51.943(P<0.001)$, with an explanatory power of $28.2 \%$ $\left(R^{2}=0.282\right)$.

The impact of the exercise values on school-activity adaptationin the general $(\beta=0.352, P<0.001)$ and moral $(\beta=0.214$, $P<0.001)$ subcategories is statistically significant; however, the impact of the status subfactor is not statistically significant.

For the fitness of the model for exercise values and adaptation to teachers, the regression model is appropriate at the level of $F=33.682, P<0.001$, with an explanatory power of $20.3 \%$ $\left(R^{2}=0.203\right)$. The impact of the exercise valueson adaptation to teachers in the moral $(\beta=0.264, P<0.001)$ and general $(\beta=0.238$, $P<0.05)$ subcategories is statistically significant; however, the impact of the status subfactor is not statistically significant.

For the fitness of the model for exercise values and adaptation to rules, the regression model is appropriate at the level of $F=49.382, P<0.001$, with an explanatory power of $27.2 \%$ $\left(R^{2}=0.272\right)$. The impact of the exercise valueson adaptation to rules in the general $(\beta=0.268, P<0.001)$, moral $(\beta=0.258$, $P<0.001)$, and status $(\beta=0.139, P<0.001)$ subcategories is statistically significant.

For the fitness of the model for exercise values and adaptation to academic activities, the regression model is appropriate at the level of $F=44.334(P<0.001)$, with an explanatory power of $25.1 \%\left(R^{2}=0.251\right)$. The impact of the exercise valueson adaptation to academic activities in the general $(\beta=0.305, P<0.001)$, moral $(\beta=0.217, P<0.001)$, and status $(\beta=0.107, P<0.05)$ subcategories is statistically significant.

\section{DISCUSSION}

From an analysis of the impact of the exercise values of US. Taekwondo trainees on school-life adaptation, the subfactors of exercise values (general, moral, and status) partly affected the subfactors of school-life adaptation (school activities, teachers, rules, and academic activities). More specifically, the general and moral values affected all of the subfactors, while the status values affected both rule adaptation and adaptation to academic activities.

Similar results were reported by previous studies. A study by on the value of taekwondo training reported that the child participants of taekwondo training in the study thought more highly of 
moral and rule compliance than the child participants of other sports, thereby providing support for the results of this study. Previous studies also show the existence of positive effects regarding the cultivation of ethical attitudes that is achieved through the nurturing of the spirits of the taekwondo trainees (Lakes and Hoyt, 2004; Lakes et al., 2013).

In addition, some existing studies report similar results regarding the positive impact of exercise values on school-life adaptation. Following ananalysis of the school-life-adaptation difference between taekwondo participants and nonparticipants. Also, Lim and Kim (2011) reported that sports activities favorably affect school-life adaptation. Therefore, it is demonstrating that long participation in taekwondo would have a positive effect on pro-social behaviors (Koo and Lee, 2014).

The results of this study indicate that taekwondo training can contribute to learning and academic-activity improvements, inspire the sociability that is necessary for school life, and promote the cooperation, unity, and school affection that are necessary for organizational life. Additionally, it is expected that healthy physical activities like taekwondo will not only mean that adolescents are steered in a beneficial direction during troubled and stressful times, but that school-life adaptation is facilitated by an inspiration of confidence, cooperation, a spirit of service, and sociability; furthermore, the adolescents will be enabled to engage in experiences such as pleasure, emotional purification, and a sense of accomplishment through their voluntary participation.

Based on this study, taekwondo helps the growth and development of children and youth, it has a greater utility in the cultivation of ideal human beings that is combined with a holistic, humanist education that fosters the formation of great personalities, and it improves physical strength through physical activities. These benefits are regarded as very favorable factors for the cultivation of the personalities of US students who can be exposed to potentially harmful social elements such as gun possession and drugs. Taekwondo training enables students to maintain a relationship with school rules, order, academic activities, and teachers; moreover, the training also helps students to form rational judgments regarding peer-related conflicts, and it the refore contributes to the educational value of public education.

\section{CONFLICT OF INTEREST}

No potential conflict of interest relevant to this article was reported.

\section{ACKNOWLEDGMENTS}

This work was supported by the National Research Foundation of Korea Grant funded by the Korean Government (NRF-2017S1A5B4055939).

\section{REFERENCES}

Chang DS, Hwang SH. The development of anger management program based on acceptance and commitment therapy for youth taekwondo players. J Exerc Rehabil 2017;13:160-167.

Kazemi M, Waalen J, Morgan C, White AR. A profile of olympic taekwondo competitors. J Sports Sci Med 2006;5(CSSI):114-121.

Kim GP. Relationship between the type of taekwondo training hall program and spiritual power. Korean J Phys Edu 2005;44:543-552.

Kim IS. Influence of elementary school children's values of athletic, motivation climate and motivational regulation to their intention of athletic participation. JKSSPE 2012;17:51-67.

Kim J, Suh W, Kim S, Gopalan H. Coping strategies to manage acculturative stress: meaningful activity participation, social support, and positive emotion among Korean immigrant adolescents in the USA. Int J Qual Stud Health Well-being 2012;7:1-10.

Kim JH, Kim GP. The relationship between taekwondo training type of physical self-efficacy and mental of martial art. Korean J Phys Edu 2000;39:37-47.

Kim KO, Seo JK. The relationships between leisure sports participation, social support, and adjustment to school life of high school students. Korean Soc Sociol Sport 2009;22:125-140.

Kim SY, Kwak JW. The effects of sports participation motive on self-esteem, self-expression and school life satisfaction in elementary students. Korean J Phys Edu 2014;53:105-116.

Koo JE, Lee KU. The relationships of elementary school students' sports participation with optimism, humor styles, and school life satisfaction. J Exerc Rehabil 2014;10:111-117.

Kwak MG, Seo BJ. The influence which the self-flexibility and the social support felt by the teenagers living in the grandparents-children families have on the adaptation to school life. J Public Welf Adm 2011;21: 75-112.

Lakes KD. The value of youth education in taekwondo training: scientific evidence for the benefits of training children. Taekwondo J Kukkiwon 2013;4:101-120

Lakes KD, Bryars T, Sirisinahal S, Salim N, Arastoo S, Emmerson N, Kang D, Shim L, Wong D, Kang CJ. The Healthy for Life Taekwondo Pilot Study: A Preliminary Evaluation of Effects on Executive Function and BMI, Feasibility, and Acceptability. Ment Health Phys Act 2013;6:181- 
188.

Lakes KD, Hoyt WT. Promoting self-regulation through school-based martial arts training. J Appl Dev Psychol 2004;25:283-302.

Lee BH, Kim KJ. Effect of taekwondo training on physical fitness and growth index according to IGF-1 gene polymorphism in children. Korean J Physiol Pharmacol 2015;19:341-347.

Lee GH. Relationship of taekwondo training to sociability development and mental health among american elementary schoolers. J Korean Alliance Martial Art 2010;12:205-220.

Lee GH, Song HS. The relationship study between taekwondo training and self-concept development among elementary school children. Korean J Phys Edu 2006;45:121-129.

Lee MJ, Cockman MJ. Values in children's sport: spontaneously expressed values among young athletes. Int Rev Sociol Sport 1995;30:337-350.

Lee MJ, Whitehead J, Balchin N. The measurement of values in sport : development of youth sport questionnaire. J Sport Exerc Psychol 2000; 22:307-326.

Lee YO, Kim YJ. Affection on school adjustment of middle school student participating in after-school physical activities. Kor J Sport 2011;9:93-
105.

Lim BJ, Kim KS. Peer relationship's network structure and decisive factors analysis of peer status among the children participating in sports club. Korean J Sociol sport 2011;24:41-62.

Schwartz SH. Universals in the content and structure of values: theoretical and empirical tests in 20countries. In Zanna MP, editor. Advances in experimental social psychology. San Diego: Academic Press; 1992. p. 1-65.

Seong $\mathrm{CH}$. Perceived values and value systems for sport participating in youth sport. Korean J Sport Psychol 2005;16:83-99.

Uu KU, Won YB. The relationship between the origin of variance occurred through participation in all of sports and school violence/adaptation. Korean J Sport Psychol 2008;19:97-113.

Watson MS, Solomon D, Battistich V, Schaps E, Solomon J. The child development project: combining traditional and developmental approaches to values education. In: Nucci L, editor. Moral development and character education: a dialogue. Berkely (CA): McCutchan Co.; 1989. p. 51-92. 